\title{
RESEARCH
}

\section{A Programmatic Approach to Peer-Led Tutoring to Assist Students in Academic Difficulty}

\author{
Angela Shogbon Nwaesei, PharmD, T. Vivian Liao, PharmD \\ Mercer University, College of Pharmacy, Atlanta, Georgia \\ Corresponding Author: T. Vivian Liao, Mercer University, College of Pharmacy, 3001 Mercer University Dr., Atlanta, GA 30341. \\ Tel: 678-547-6221. Email: liao_tv@mercer.edu
}

Submitted May 13, 2021; accepted January 12, 2022; ePublished January 2022

Objective. To evaluate a peer-led tutoring program to assist students in academic difficulty in the didactic curriculum across multiple courses using one-on-one and large group peer-led sessions, and to evaluate the academic performance and perceptions of students in this program.

Methods. This study involved student pharmacists in their second through fourth professional year (P2 - P4) who served as tutors, and P1 - P3 tutees. Tutoring was offered in multiple didactic courses using one-on-one and large group peer-led sessions. Didactic curriculum completion rates and perceptions of the program were assessed.

Results. A total of 463(47\%) P1 - P3 student pharmacists utilized the one-on-one or large group peer-led tutoring services in 28 courses across four academic years. Tutored students had a lower grade distribution compared to non-tutored students suggesting a more at-risk group for academic failures and dismissals. Despite this, the didactic curriculum completion rate was comparable between tutored and the non-tutored students during the study period, suggesting a benefit of the program in reducing academic dismissals of the at-risk tutored students. On the perceptions survey, $95 \%$ of respondents felt they improved their study habits and $92 \%$ felt more confident in their ability to succeed.

Conclusion. This peer-led tutoring program appeared to be successful in providing comparable didactic curriculum completion rates of tutored students who were an at-risk group for academic failures and dismissals compared with nontutored students. The tutoring program structure and design may be a useful tool for other colleges of pharmacy as they seek ways to assist students.

Keywords: peer-led tutoring, students in academic difficulty, didactic curriculum, one-on-one tutoring, group peer-led tutoring 


\section{INTRODUCTION}

Peer-assisted learning (PAL), a broad term that describes diverse learning processes between students at or near the same academic level, comprises peer-tutoring, peer-teaching, peer-mentorship, peer-assessment, and peer-modeling. ${ }^{1,2}$ PAL has been reported in health professions education, including medicine, nursing, physical therapy and pharmacy, to provide academic support to students ${ }^{1,3-13}$. Since students' academic success is an important measure of quality education, institutions monitor student performance and provide academic support services to students in academic difficulty ${ }^{14}$ To foster student success, peer-led tutoring, a well-recognized approach to improve classroom performance, can provide oneon-one student intervention and support. ${ }^{1,3}$ In health professions education, studies on PAL to support students in academic difficulty have been reported. ${ }^{4,15,16}$ Two studies evaluating peer-led supplemental instruction for at-risk medical students reported improved outcomes in the tutored group including higher test scores and lower exam failure rates. ${ }^{15,16}$ Ramsey and colleagues described a peer-mentor-tutor program to support student nurses from disadvantaged backgrounds who were at risk for academic difficulty and reported on factors that could impact student performance. ${ }^{4}$ In pharmacy education, one study evaluated the effectiveness of a mandatory academic enrichment program for struggling first-year student pharmacists and reported lower course failure rates compared to low-performing students in the same course from the previous two years. ${ }^{17}$

Some limitations characterize studies in pharmacy education that utilized PAL to teach clinical skills, didactic courses, or in the experiential setting. ${ }^{1,6-13,18-21}$ A singular approach to delivery of the PAL program was most commonly utilized which included presentations, teaching sessions, seminars or workshops. ${ }^{6,713,18,21}$ Many of these studies utilized survey-based assessment to evaluate students' confidence and perceptions, and not all studies included an objective evaluation of tutee performance. ${ }^{7,10-13,19}$ Studies that included an objective evaluation reported performance on a course assessment or examination. ${ }^{6,20,22}$ Only one study in pharmacy education reported course pass rates as an objective evaluation, but the study period was limited to a term of one semester. ${ }^{17}$

To aid with successful progression of student pharmacists through the curriculum, academic support needs to be provided to students that spans across the curriculum, with multiple approaches to delivery of the academic support and an objective evaluation of students' performance. The objective of this study was to evaluate a programmatic structured peerled tutoring program to assist students in academic difficulty in the didactic curriculum across multiple courses, using one-on-one and large group peer-led sessions, and to evaluate the academic performance and perceptions of students in this program. We hypothesized that this program would prevent course failures of students utilizing the program and yield positive perceptions of the program.

\section{METHODS}

This study evaluated a structured peer-led tutoring program that utilized one-on-one and large group peer-led tutoring to assist students in academic difficulty in the didactic curriculum. The study, conducted over four academic years (2013 - 2017), occurred at Mercer University College of Pharmacy in Atlanta, Georgia. At this institution, student pharmacists receive a traditional four-year curriculum, which comprises three years of didactic education followed by experiential education during the last year. The study institution's local chapter of the Rho Chi Society, with support from the College of Pharmacy administration, developed and offered the peer-led tutoring program to assist students in academic difficulty. The Rho Chi Society, the academic honor society in pharmacy, recognizes students with distinguished scholarly achievements, representing the top $20 \%$ of the graduating class. ${ }^{23}$

Student pharmacist members of the Rho Chi Society in their second through fourth professional year (P2 - P4) served as tutors, while tutees were first through third professional year (P1 - P3) student pharmacists. Tutors selected the courses they were interested in tutoring and delivered peer-led instruction in completed courses. As the Rho Chi Society members, tutors had demonstrated successful and distinguished academic performance. Tutoring services, consisting of one-on-one and large group peer-led sessions, were offered in various first through third professional year courses in the didactic curriculum.

Prior to participating in the program, faculty advisors for the Rho Chi Society created and distributed a standard operating procedure for the tutoring program to tutors, tutees and course coordinators. Additionally, all tutors received a one-hour training at the beginning of each semester on these standard operating procedures and on effective ways to conduct the sessions. This in-person training was delivered in the form of verbal instruction, role play, and journal article discussion. Although the tutee grades were not released to the tutors, the advisors emphasized the importance of student privacy during the training session, because the tutees may disclose their performance in confidence with the tutor during the one-on-one session. 


\section{One-on-One Tutoring Sessions}

Students in academic difficulty, defined as a score less than $70 \%$ on an exam in a course (which was considered a failing grade), qualified to receive fee-waived, one-on-one tutoring sessions, and the students had to request this service to be assigned a tutor. One-on-one tutoring was available to students who were not in academic difficulty at a fee of $\$ 20$ per hour that was paid to the Rho Chi local chapter. Prior to each session, the tutees notified the tutors about the topics to review during the session. The tutors instructed the tutees to prepare questions about difficult or unclear concepts. As such, the tutor tailored the session based on the expressed needs of the tutee and prepared questions to assess tutees understanding of the material, and foster tutees application of course concepts. After completion of each one-on-one session, tutees were asked to complete an online evaluation form to document the occurrence of the session and to provide feedback on the quality of the session and their satisfaction and perceptions of the tutoring program. Tutees were asked to indicate their agreement with the following statements on a Yes or No scale: "as a result of this session, I improved my study strategies" and "as a result of this session, I feel more confident about my ability to succeed in this course."

\section{Large Group Peer-Led Sessions}

At the beginning of each semester, course coordinators contacted the Rho Chi faculty advisors to request the large group peer-led sessions in their course. Typically, the large group peer-led sessions occurred once a week and involved one to two tutors. Tutors led a review session at a set time, and the review session was open to any student to attend at no cost. Prior to the session, tutors contacted course faculty to identify focus areas for the session, and sent any prepared presentation or session content to course faculty for feedback. For the large group sessions, tutors reviewed key concepts in the course that the tutors and course faculty identified as important focus areas. Typically, the tutors engaged the attendees with an interactive format, such as question and answer sessions, and sometimes instructional games.

To improve student accessibility, the College of Pharmacy administration promoted these services and instructed students and course coordinators on the process to request tutoring. The Rho Chi faculty advisors set up the large group peer-led sessions two to three days prior to each course exam. Administrative support personnel and course coordinators notified students of the sessions schedule through weekly electronic messages. Additionally, the administrative support personnel disseminated weekly messages to faculty advisors about students' academic performance. The faculty contacted these students to encourage utilizing one-on-one tutoring and group peer-led sessions. Students were expected to initiate the one-on-one tutoring request by contacting the tutoring program administrative assistant. Once the student requested the one-on-one tutoring, administrative support assisted with finding tutor availability, setting up one-on-one sessions, confirming eligibility for fee-waived one-on-one tutoring for students in academic difficulty, and tracking performance in the tutored course.

Data on students and course performance were obtained from the Registrar using a utility incorporated into the administrative software. For initial data collection, we used Microsoft Excel and imported those files into Statistical Package for the Social Sciences (SPSS) Release 27.0.1.0 for analytical data management, interim calculations, and statistical calculations. ${ }^{24} \mathrm{We}$ assessed the characteristics of students utilizing the program, their usage of tutoring services over the four academic years, and course performance. Since students could be tutored in multiple courses, some tabulations included students multiple times which we designated as student by course; other tabulations are compiled across a student's overall performance. For data collection purposes, we tracked student outcomes each time a student utilized tutoring in a course during a specific term (student by course by term). Two course terms (fall and spring semesters) comprised one academic year. The student by course by term metric allows for repeat measures to account for students tutored in the same course multiple times or a different course in the same term. Specifically, students tutored in one term for one course could be counted again for subsequent tutoring encounters that occurred within the same course and term or in a different course during a different term. To evaluate the program and its impact, we assessed the academic performance of students (and student by course for some metrics) participating in the program and their didactic curriculum completion rates during the study period, in comparison to students who did not utilize the program. The didactic curriculum completion rate was assessed by comparing the proportion of students successfully completing the didactic component of the curriculum (P1 - P3) between tutored and non-tutored students. This was defined as students who were not academically dismissed due to earning 3 failing grades in the curriculum. Large group peer-led sessions data for courses which were consistently offered for at least 3 out of the 4 academic years reviewed were included in the analysis. Statistical tests were conducted using Pearson Chi-square for data which did not fail the Kolmogorov-Smirnov test for Normality, ie, data which appeared to conform to a Normal distribution, and using the Mann-Whitney U Test otherwise. Tutees' satisfaction and perceptions of the one-on-one tutoring services were reported using descriptive statistics. One survey per tutee per course was evaluated and since a student could receive tutoring in multiple courses 
during the study period, more than one survey per student could have been received. For per-student tabulations, the predominant or median response across course was assigned to the respective student. Institutional Review Board approval was obtained from the study institution.

\section{RESULTS}

During the study period, a total of 463(47\%) P1 - P3 student pharmacists utilized the tutoring program in 28 courses (Table 1). Over the four academic years in 28 didactic courses, we tracked a total of 12,783 students by course by term combinations. The courses in which tutoring services were provided ranged from P1 foundational courses such as Pharmaceutics, Pharmacy Law \& Ethics, Principles of Pharmacokinetics, to P2 and P3 disease-based modules. The five most common courses in which tutoring sessions were offered were Nervous System Disorders I (17\%), Infectious Disease II (8.1\%), Infectious Disease I (6.8\%), Endocrine Disorders (6.8\%), and Nervous System Disorders II (6.1\%).

The usage of the tutoring services, when evaluating student by course by term usage, increased substantially in 2013-2014 and remained consistently over 50\% of students during all terms through 2016-2017. (Pearson Chi-square $\mathrm{P}<0.001$ ) (Table 2). In relation to the tutor resources utilized to support this program, tutors spent a total of 527.5 hours delivering the one-on-one and large group peer-led sessions over the four academic years included in this study. This included 324.5 hours spent delivering one-on-one sessions, and 203 hours spent with the large group peer-led sessions. While specific tutor data was not tracked, the number of tutors each year varied based on the number of Rho Chi eligible students in each class year and ranged from $30-45$ P2 - P4 tutors. All Rho Chi students were encouraged to tutor at least one session to help with the lift of the program, however, this was not always possible for P4 students due to Advanced Pharmacy Practice Experience responsibilities.

Categorical and numerical analysis of overall course grade performance of non-tutored versus tutored students during the study period revealed a lower grade distribution in the tutored students, suggesting a more at-risk group for academic failures and dismissals. Specifically, there was a statistical difference between overall A-F course grade performance using table counts (Pearson Chi-sq $p<.001$ ) of non-tutored versus tutored students, the latter having an A-F grade distribution skewed toward $\mathrm{F}$. This lower grade distribution was also confirmed numerically when letter grades in each course over the study period were converted to scores ranging from $\mathrm{F}=0, \mathrm{C}=2, \mathrm{C}+=2.5, \mathrm{~B}=3, \mathrm{~B}+=3.5$ and $\mathrm{A}=4$ (Mann-Whitney U test $p<.001$ ). Despite this, there was no statistical difference between the overall didactic curriculum completion rates of tutored versus non-tutored students during the study period (Pearson Chi-sq. $p=.192$ ) suggesting a benefit of the program in reducing academic dismissals of the at-risk tutored students (Table 3 ).

Sixty-four percent of students responded on perceptions and satisfaction with the one-on-one tutoring program. A total of $95 \%$ of respondents agreed with the statement that as a result of the tutoring session, they improved their study strategies and $92 \%$ agreed with the statement that as a result of the tutoring session, they feel more confident about their ability to succeed in the course (Table 4).

\section{DISCUSSION}

This is the first study, to our knowledge, that evaluated the successful delivery of a programmatic approach to a structured peer-led tutoring program designed to assist students in academic difficulty, across multiple courses over four academic years in the didactic pharmacy curriculum. This peer-led tutoring program used two different approaches, oneon-one and large group peer-led sessions, to engage learners, and to provide academic support. The didactic curriculum completion rate was reported as an objective assessment of the tutoring program. Although the tutored students in this study had a lower overall grade distribution compared to non-tutored students, we observed a similar didactic curriculum completion rate between the two groups suggesting a benefit of the program in reducing academic dismissals of the at-risk tutored students. The grade distribution of the tutored and non-tutored students indicated that the tutoring program was effective at targeting students in academic difficulty, which achieved the College's goal to provide academic support services, including to at-risk students who failed an exam.

In this study, two delivery approaches were used, including one-on-one and large group peer-led sessions. The large group peer-led sessions were implemented after the individual tutoring sessions had been ongoing, as a way to expand the reach of the program and to overcome potential barriers of hesitancy to participate in one-on-one sessions, and appeal to students' comfort with group learning and peer-led instructions. The one-on-one tutoring service also presented a valuable aspect to this program because tutors had the opportunity to customize the session based on the unique needs of the tutees and to better provide more directed peer-led instruction. Many studies describing PAL services in the pharmacy curriculum reported a singular approach to delivery of these services within the program, including teaching sessions, presentations, seminars, or workshops. ${ }^{6,7,13,18,21}$ Tang and colleagues reported the design and evaluation of a student-led managed care elective that involved peer-led discussion-based presentations while Lehrer and colleagues described the 
utilization of peer-led problem-based seminars delivered by second-year medical students to first-year medical and pharmacy students. ${ }^{7,21}$

Although an objective evaluation of student performance is important to demonstrate the value of peer teaching or peer-led tutoring, previous studies that included an objective measure to assess student performance reported varied outcomes. ${ }^{15,17,25}$ A study on peer-tutoring for physical therapy students compared grades from an advanced physiology course to the scores on an introductory physiology course. ${ }^{25}$ After converting the letter grades to an eleven-point numerical score, the course grades in the advanced physiology course were lower for the tutored and untutored students, but the decline in scores was significantly less in the tutored group $(p=.021) .{ }^{25}$ Bridgham and colleagues compared the effectiveness of tutoring across multiple courses over two academic years and reported that at-risk medical students who participated in $80 \%$ of the tutoring sessions achieved higher test averages than predicted in seven of the twelve tests compared with non-tutored students $(p \leq .05) .{ }^{15}$ In pharmacy education Dirks-Naylor and colleagues describe a group peerled tutoring program that targeted first-year student pharmacists in academic difficulty and reported that the course failure rate for the intervention group was $6.7 \%$ compared to the failure rate of the previous two years, $11.1 \%$ and $9.4 \%$, respectively. ${ }^{17}$ In our study, we identified the didactic curriculum completion rate as an important and unique objective measure of student performance and success since it affects progression through the curriculum. To assess this measure, we evaluated the attainment of three course failures during the study period, which leads to an academic dismissal. Despite the tutored students having a lower academic performance, no statistical difference was observed in the didactic curriculum completion rates between tutored and non-tutored students. Based on the didactic completion rate, the programmatic tutoring program appears to be effective as a preventative strategy to reduce course failures. Beyond course failures, this tutoring program could be used as an intervention to provide academic support and minimize the need for course remediation which may have an impact in the experiential curriculum as poor academic performance, including course failures and lower grade point averages, is a risk factor associated with failure or poor performance on advanced pharmacy practice experiences. ${ }^{26}$

Currently, existing studies on PAL in the pharmacy literature evaluated students' perceptions, skills gained, and attitudes. ${ }^{7,10-13,18,19,21,22}$ Rodis and colleagues conducted a survey and reported that a majority of students agreed that the student-peer mentoring o $\mathrm{n}$ a drug information question improved the likelihood of tutees receiving a higher grade. ${ }^{11}$ In another study by Zhang and colleagues, students reported that peer-led study groups helped them gain confidence and reach competency on the exam material. ${ }^{20}$ Our study revealed similar findings where the majority of student respondents agreed that as a result of the one-on-one tutoring session, they improved their study strategies and felt more confident in their ability to succeed in the course.

This study had a few limitations. The peer-led tutoring program may not have been the only intervention that students in academic difficulty utilized to help improve their success in the course. In addition, we did not control for other factors that may correlate with success, including undergraduate GPA and PCAT scores. The evaluation of successful completion of the didactic curriculum was conducted based on data collected over the four-year study period in 28 courses for which tutoring was received. Individual student data was not tracked from the beginning to the end of their didactic curriculum and so may not have captured future course failures in the curriculum beyond the study period for both tutored and non-tutored students. Lastly, our study was conducted at one institution which may limit application to other colleges of pharmacy. We plan to continue to refine our tutoring program to meet student needs towards their academic success. Specifically, based on student request, we migrated to recording the in-person large group sessions and making it available to students as an additional studying tool and where personal schedules prohibited session attendance. In addition, due to the COVID-19 pandemic and the challenges associated with in-person gatherings, the large group peerled sessions shifted to a live online platform and session recordings made available to students.. Our description of the delivery of a programmatic approach to a structured peer-led tutoring program in the didactic curriculum across multiple courses using two delivery approaches may help provide insights to other Colleges of Pharmacy on the design of such a program, logistics involved and program evaluation.

\section{CONCLUSION}

A programmatic approach to a structured peer-led tutoring program designed to assist students in academic difficulty was successfully delivered across multiple courses in the didactic curriculum over four academic years. This peer-led tutoring program appeared to be successful in providing comparable didactic curriculum completion rates of tutored students who were an at-risk group for academic failures and dismissals compared with non-tutored students. Our peer-led tutoring program for academic support may be a useful reference for other colleges of pharmacy. 


\section{ACKNOWLEDGEMENT}

We would like to acknowledge Thomas H. Taylor, Jr., MS, a biostatistician at Mercer University College of Pharmacy, for his time and expertise in statistical analyses.

\section{REFERENCES}

1. Aburahma MH, Mohamed HM. Peer teaching as an educational tool in Pharmacy schools; fruitful or futile. Curr Pharm Teach Learn. 2017;9(6):1170-1179. doi:10.1016/j.cptl.2017.07.026

2. Henning JM, Weidner TG, Marty MC. Peer assisted learning in clinical education: literature review. Athl Train Educ J. 2008;3(3):84-90. doi:10.4085/1947-380X-3.3.84

3. Santee J, Garavalia L. Peer tutoring programs in health professions schools. Am J Pharm Educ. 2006;70(3). Accessed September 5, 2019. https://www.ncbi.nlm.nih.gov/pmc/articles/PMC1636940/

4. Ramsey P, Blowers S, Merriman C, Glenn LL, Terry L. The NURSE Center: a peer mentor-tutor project for disadvantaged nursing students in Appalachia. Nurse Educ. 2000;25(6):277-281.

5. Batchelder AJ, Rodrigues CMC, Lin LY, Hickey PM, Johnson C, Elias JE. The role of students as teachers: four years' experience of a large-scale, peer-led programme. Med Teach. 2010;32(7):547-551. doi:10.3109/0142159X.2010.490861

6. Cole JD, Ruble MJ, Donnelly J, Groves B. Peer-assisted learning: clinical skills training for pharmacy students. Am J Pharm Educ. 2018;82(6). doi:10.5688/ajpe6511

7. Tang S, Smith J, Lau W, et al. Managed care peer-led teaching: an innovative learning approach outside the college of pharmacy core curriculum. J Manag Care Spec Pharm. 2017;23(7):755-759. doi:10.18553/jmcp.2017.23.7.755

8. Lindblad AJ, Howorko JM, Cashin RP, Ehlers CJ, Cox CE. Development and evaluation of a student pharmacist clinical teaching unit utilizing peer-assisted learning. Can J Hosp Pharm. 2011;64(6):446-450.

9. Lull ME, Mathews JL. Online self-testing resources prepared by peer tutors as a formative assessment tool in pharmacology courses. Am J Pharm Educ. 2016;80(7). doi:10.5688/ajpe807124

10. Rodis JL, Backo J, Schmidt BM, Pruchnicki MC. Student-peer mentoring on a drug information response. Am J Pharm Educ. 2014;78(2). doi:10.5688/ajpe78238

11. Kan K, Chow J, Ng K, Malik R, Steenhof N. Peer-assisted learning in general internal medicine: pharmacy students' perspectives. Can J Hosp Pharm. 2018;71(2):135-139.

12. Kolar C, Hager K, Janke KK. Using peer teaching to introduce the Pharmaceutical Care Model to incoming pharmacy students. Curr Pharm Teach Learn. 2018;10(2):170-177. doi:10.1016/j.cptl.2017.10.011

13. Gay D, Rutter P. The effect of cross year peer tutoring in pharmacy dispensing classes: the wolverhampton experience. Pharm Educ. 2013;13. Accessed May 8, 2021. https://pharmacyeducation.fip.org/pharmacyeducation/article/view/255

14. Mattingly TJ, Romanelli F, Cain J, Schlesselman LS. Measuring Up - defining the quality of pharmd programs. Am J Pharm Educ. 2017;81(9). doi:10.5688/ajpe6071

15. Bridgham RG, Scarborough S. Effects of supplemental instruction in selected medical school science courses. Acad Med J Assoc Am Med Coll. 1992;67(10 Suppl):S69-71. doi:10.1097/00001888-199210000-00043

16. Sawyer SJ, Sylvestre PB, Girard RA, Snow MH. Effects of supplemental instruction on mean test scores and failure rates in medical school courses. Acad Med J Assoc Am Med Coll. 1996;71(12):1357-1359. doi:10.1097/00001888199612000-00021

17. Dirks-Naylor AJ, Cook C, Nhean P. Development and assessment of an academic performance enrichment program for low-performing, first-year pharmacy students. Adv Physiol Educ. 2019;43(3):259-265. doi:10.1152/advan.00184.2018

18. Walpola RL, Fois RA, McLachlan AJ, Chen TF. Evaluating the effectiveness of a peer-led education intervention to improve the patient safety attitudes of junior pharmacy students: a cross-sectional study using a latent growth curve modelling approach. BMJ Open. 2015;5(12). doi:10.1136/bmjopen-2015-010045

19. Lipton HL, Lai CJ, Cutler TW, Smith AR, Stebbins MR. Peer-to-Peer Interprofessional Health Policy Education for Medicare Part D. Am J Pharm Educ. 2010;74(6):102. doi:10.5688/aj7406102

20. Zhang B, Kim S, Xiao Y, et al. A student initiative to implement peer-led study groups for a pharmacogenomics course: Evaluation of student performance and perceptions. Curr Pharm Teach Learn. 2020;12(5):549-557. doi:10.1016/j.cptl.2020.01.013

21. Lehrer MD, Murray S, Benzar R, et al. Peer-led problem-based learning in interprofessional education of health professions students. Med Educ Online. 2015;20:28851. doi:10.3402/meo.v20.28851

22. Chambers SL, Schmittgen J, Allan CR. Evaluation of peer teaching in a pharmaceutical care laboratory. 2000;64:6. 
23. The Rho Chi Pharmacy Honor Society. Accessed May 8, 2021. https://rhochi.org/

24. IBM SPSS Statistics for Windows, Version 27.0. Armonk, N.Y: IBM Corp.; 2020.

25. Lake DA. Peer tutoring improves student performance in an advanced physiology course. Am J Physiol. 1999;276(6 Pt 2):S86-92. doi:10.1152/advances.1999.276.6.S86

26. Call WB, Grice GR, Tellor KB, Armbruster AL, Spurlock AM, Berry TM. Predictors of student failure or poor performance on advanced pharmacy practice experiences. Am J Pharm Educ. 2020;84(10):ajpe7890. doi:10.5688/ajpe7890 


\section{Table 1. Student and Course Characteristics Over Four Academic Years}

\begin{tabular}{ll}
\hline Student and Course Characteristics & $\mathrm{n}(\%)$ \\
\hline Number of students who did not utilize any tutoring services, $\mathrm{n}(\%)$ & $513(52.6 \%)$ \\
Number of students utilizing tutoring services, $\mathrm{n}(\%)$ & $463(47.4 \%)$ \\
Number of students utilizing one-on-one tutoring services, $\mathrm{n}(\%)$ & $122(12.5 \%)$ \\
Number of students utilizing large group tutoring, $\mathrm{n}(\%)$ & $341(34.9 \%)$ \\
Number of students utilizing both services, $\mathrm{n}(\%)$ & $50(5.1 \%)$ \\
Total number of students & $\mathbf{9 7 6}$ \\
Number of courses, $\mathrm{n}$ & 28 \\
First professional year courses, $\mathrm{n}(\%)$ & $9(32 \%)$ \\
Second professional year courses, $\mathrm{n}(\%)$ & $9(32 \%)$ \\
Third professional year courses, $\mathrm{n}(\%)$ & $10(36 \%)$ \\
Number of students by course by term & \\
First professional year courses & $5105(39.9 \%)$ \\
Second professional year courses & $3800(29.7 \%)$ \\
Third professional year courses & $3878(30.3 \%)$ \\
Total Number of Students by Course by Term & $\mathbf{1 2 , 7 8 3}$ \\
\hline
\end{tabular}


Table 2. Student by Course by Term Usage of Tutoring Services

\begin{tabular}{lll}
\hline Academic Year & Tutored & Total \\
\hline $2013-2014$ & $1405(41.3 \%)$ & 3401 \\
$2014-2015$ & $1728(54.0 \%)$ & 3202 \\
$2015-2016$ & $1645(52.3 \%)$ & 3142 \\
$2016-2017$ & $1689(55.6 \%)$ & 3037 \\
$\mathbf{2 0 1 3}-\mathbf{2 0 1 7}$ & $\mathbf{6 4 6 7}(\mathbf{5 0 . 6 \%})$ & $\mathbf{1 2 , 7 8 3}$ \\
\hline
\end{tabular}

Pearson chi-square $p<.001$ 
Table 3. Didactic Curriculum Completion Rate of Tutored vs. Non-Tutored Students

\begin{tabular}{ll}
\hline Students & Completion Rate \\
\hline Non-Tutored $(\mathrm{n}=513)$ & $504(98.2 \%)$ \\
Tutored $(\mathrm{n}=463)$ & $449(97.0 \%)$ \\
Total $(\mathbf{N}=\mathbf{9 7 6})$ & $\mathbf{9 5 3}(\mathbf{9 7 . 6 \% )}$ \\
\hline
\end{tabular}

Pearson Chi-square $p=.192$ 
Table 4. One-on-One Tutoring Program: Tutee's Satisfaction and Perceptions of the Program's Impact

\begin{tabular}{ll}
\hline Statements & Yes, n (\%) \\
\hline I improved my study strategies $(\mathrm{n}=77)$ & $73(95 \%)$ \\
I feel more confident in my ability to succeed in course $(\mathrm{n}=78)$ & $72(92 \%)$ \\
\hline
\end{tabular}

Response rate of $64 \%$ ( $\mathrm{N}=122$ students participated in one-on-one tutoring program) 